\title{
Cloud Computing In Education: Potentials And Challenges For Bangladesh
}

\author{
Md Aminur Islam ${ }^{1}$, Faisal Bin Abul Kasem ${ }^{1}$, Shakib-Uz-Zaman Khan ${ }^{1}$, Md. Tarek \\ Habib $^{1}$, Farruk Ahmed ${ }^{2}$ \\ ${ }^{1}$ Department of Computer Science and Engineering, Daffodil International University, \\ Dhaka, Bangladesh \\ ${ }^{2}$ Department of Computer Science and Engineering, Independent University, Bangladesh
}

\begin{abstract}
Cloud Computing is an emerging technology. It is a growing technology which can change traditional IT systems. It plays a major role in today's technology sector. People are using it every day through one way or another. Education sector is not out of this phenomenon. At the present time the teaching method is changing and students are becoming much technology based and therefore it is necessary that we think about the most recent technologies to incorporate in the teaching and learning methods. By sharing Information technology related services in the cloud, educational institutions can better concentrate on offering students, teachers, faculty and staff the essential instruments. Bangladesh is a developing country. So applying this technology on education sector is a huge challenge for Bangladesh. In this paper it is discussed that how Bangladesh can be benefited by applying cloud in education and its challenges followed by some case studies and success stories.
\end{abstract}

\section{KEYWORDS}

Cloud in Education, Cloud Computing, Bangladesh, Cloud Computing in Bangladesh, Cloud in Bangladeshi Education.

\section{INTRODUCTION}

The world is changing rapidly. Day by day people are engaging more and more in ICT. Education is not out of this phenomenon. Most of the educational institutes' students now rely on web based educational system. From lectures to assignment submission, everything is now online based. There comes the necessity of cloud.

The idea of computing in a "cloud" finds back to the origins of leverage computing, a concept that computer scientist John McCarthy publicly proposed in 1961: If computers of the kind I have suggested become the computers of the future, then computing may someday be formulated as a public leverage just as the telephone system is a public leverage. The computer leverage could become the basis of a new and important industry [1].

Cloud computing is a buzzing word now-a-days in ICT industry. It means delivery of computing resources over the internet. In one word, cloud computing is nothing but a bunch of highly scalable computers working together somewhere and giving service to an end user over the internet. It can also be visualized as doing one's computing work using hardware resources from another place. The word "Cloud computing" was first used by Compaq in 1996 and popularization was done by Amazon.com when they had introduced Elastic Compute Cloud [2]. Cloud users can benefit from other organizations delivering services associated with their software, data and other computing needs on the behalf, without need to run the usual software of their computer.

DOI: $10.5121 /$ ijcsea.2017.7502 
Cloud computing is the next stage in the slope of the internet, it assists the means through which everything - from computing power to computing infrastructure, applications and business operations - can be delivered to you as a service wherever and whenever you demand them [3]. A service provider is necessary in cloud computing. The providers serve in different ways.

SaaS: Software as a Service is a software certification and delivery model where a fully operational and complete software product is delivered to users over the web on a subscription base. SaaS is used for Email, CRM, Communication, Virtual Desktop, games etc.

PaaS: In Platform as a Service model, cloud providers provide computing platform, usually programming language running environment (IDE), operating system, database and web servers. User can easily develop and run their desired software from the cloud platform without the cost and complexity of purchasing. PaaS is used for web server, database, development tools etc.

IaaS: Infrastructure as a Service model provides core IT services such as Virtual machines, Servers, storage, load balancers, network, security, compute, middleware devices, block and file or object storage etc [4]. These service models display on the Figure-2.

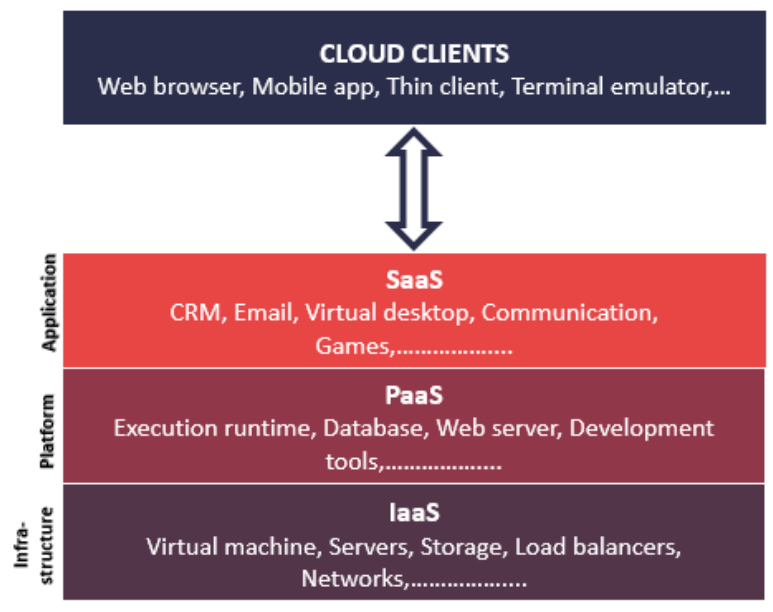

Figure 2: Cloud computing service models arranged as layers in a stack

The NIST [5] defines Cloud computing Deployment models are of four types.

Private Cloud: The Private cloud infrastructure is prepared for individual use by a single organization consisting of multiple clients.

Public Cloud: The Public cloud infrastructure is prepared for open use by the general people. It may be managed, owned, and operated by an academic, business, or government organization, or some union of them.

Community Cloud: Community cloud infrastructure is prepared for exclusive use by an earmarked community of clients from organizations that have shared concernments.

Hybrid Cloud: The formation of multiple discrete cloud infrastructures stand outstanding natures is the infrastructures of Hybrid cloud, but are tied together by patterned technology that enables data and application transportability. Development model is shown in figure-3 based on the information provided on Wikipedia. 


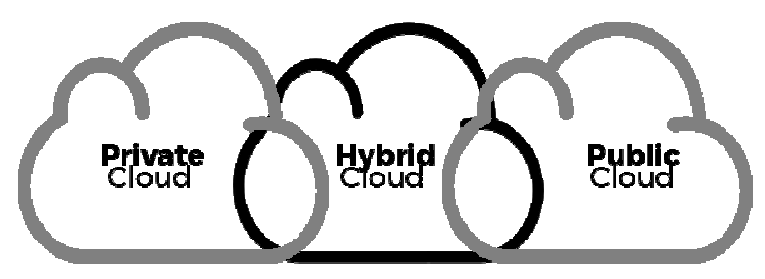

Figure 3: Cloud Computing Types

Some characteristics of cloud computing according to NIST [6],

On-demand Self-service: A client can unilaterally dispense computing capabilities.

Broad network access: Abilities are obtainable over the network and perceived through standard systems that raise use by different sleazy consumer platforms.

Resource pooling: The provider's computing resources are pooled to distribute many customers using a multiple-tenant pattern, with various virtual and physical resources dynamically assigned and reassigned following to client need.

Rapid elasticity: Abilities can be opened and made elastically.

Measured service: Cloud systems automatically control and optimize resource use by leveraging a metering capability at some level of abstraction appropriate to the type of service.

This paper focuses on application of cloud in education so technical sides are not discussed here. Many companies such as "Microsoft", "Google", "Amazon.com", "Wolframalpha.com" and "Tutorialspoint Codingground" are now serving cloud technology to educational institutions and students.

\section{LITERATURE REVIEW}

Lots of research has been done about advantages, challenges and applications of cloud computing. Banerjee provided overview of researches performed at HP Labs in the article "An Intelligent IT Infrastructure for the Future" [7]. Delic and Riley assess the current state of enterprise knowledge management, describe architectural views of cloud and discuss briefly the underlying technologies [8]. Current world is running towards Internet of Things (IoT). Piyare and Lee discussed about integrating wireless sensor network to the cloud services for data collection and sharing [9]. Cloud computing consumes a significant amount of power. Kuribayashi proposed some policies to reduce power consumption [10]. The most concerned area of cloud was its security. Ragib Hasan has done a research on it and won the NSF CAREER Award [11]. Hussein and Khalid also made a survey on cloud computing security challenges and solutions and proposed a model for cloud computing security [12]. Others are also working on this. At present time it's not a big concern anymore. Users can set their privacy demands with service providers. Recent researches prove that educational institutes and students can be benefited a lot from cloud computing. Tuncay Ercan reviewed what the cloud infrastructure will provide to education sector and how the teachers and students can be benefited more [13]. While Anjali Jain and U.S Pandey discussed about the role of cloud computing in higher education [14]. Microsoft provided an overview about the cloud services that can be used in education, pointed out the benefits, briefly described security issues, tips about planning and the services they are providing under Microsoft Live@edu [15]. UNESCO IITE discussed in their policy paper about cloud. How cloud is being applied in education, benefits, risks, guidelines and future scenario were described [16]. Google first deployed App for Education in October 2006 to Arizona State University [17]. 


\section{ApPlication in EdUCATION}

The cloud industry is emerging day by day. People are leaning to it for its on demand policy. A user can have storage or computational power as much as he need at instant without worrying about hardware.

Public Information Technology cloud service revenue in 2018 is forecasted to be $\$ 127$ Billion worldwide. By 2018 Managed services is projected to touch \$256 Billion. Flourishing markets are forecasted to be $21 \%$ of the worldwide public Information Technology cloud services market by 2018.[18] Figure 5 shows worldwide public IT cloud service based on the info provided in Microsoft Cloud Landscape Update, 2015, (RHP).

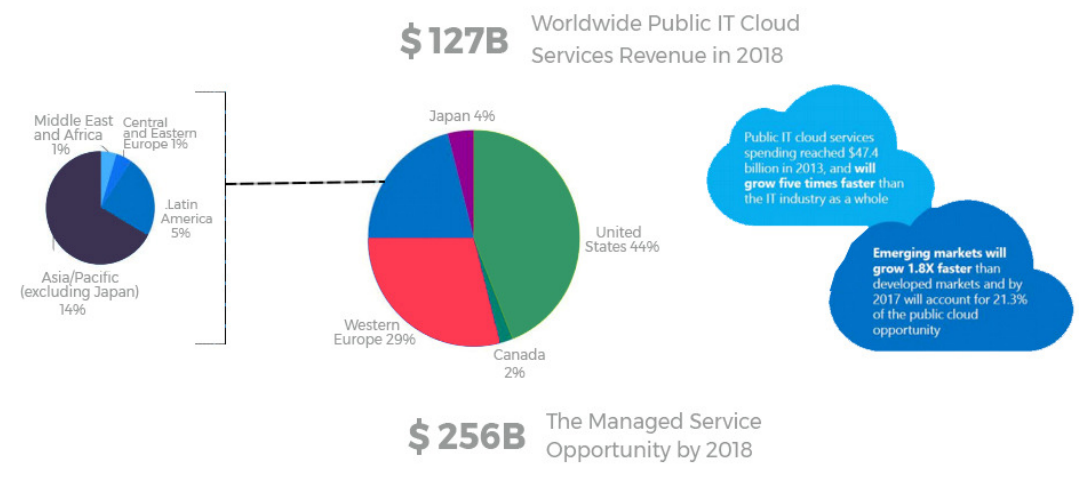

Figure 5: Regional share in Cloud Computing

According to Eurostat survey [19] use of the cloud computing services in enterprises in different countries in 2016 shown in Table 1.

In table 2 a usage survey of cloud (2012) in different sectors of USA shows that $43 \%$ of cloud usage in higher education sector [20]. Needless to say that the percentage in 2017 is definitely more due to technological and security advancement. Table 2 represents the usage survey of cloud (2012) in different sectors of USA.

Table 1: Use of cloud computing services, 2016

\begin{tabular}{|l|l|l|l|l|l|l|l|l|l|}
\hline & $\begin{array}{l}\text { Use of } \\
\text { Cloud } \\
\text { Computing }\end{array}$ & Email & $\begin{array}{l}\text { Storage } \\
\text { of files }\end{array}$ & $\begin{array}{l}\text { Hosting the } \\
\text { enterprise's } \\
\text { database(s) }\end{array}$ & $\begin{array}{l}\text { Office } \\
\text { Software }\end{array}$ & $\begin{array}{l}\text { Financial or } \\
\text { accounting } \\
\text { software } \\
\text { applications }\end{array}$ & $\begin{array}{l}\text { CRM } \\
\text { software } \\
\text { applications }\end{array}$ & $\begin{array}{l}\text { Computing } \\
\text { power for } \\
\text { enterprise's } \\
\text { own } \\
\text { software }\end{array}$ \\
\hline & \%enterprises & \%enterprises using the cloud & \multicolumn{5}{l|}{} \\
\hline EU28 & 21 & 65 & 62 & 44 & 41 & 32 & 27 & 21 \\
\hline Belgium & 28 & 57 & 66 & 47 & 47 & 47 & 33 & 28 \\
\hline Bulgaria & 7 & 65 & 58 & 57 & 44 & 30 & 20 & 17 \\
\hline $\begin{array}{l}\text { Czech } \\
\text { Republic }\end{array}$ & 18 & 76 & 49 & 31 & 40 & 31 & 22 & 21 \\
\hline Denmark & 42 & 68 & 70 & 52 & 49 & 45 & 33 & 33 \\
\hline Germany & 16 & 49 & 63 & 33 & 31 & 26 & 18 & 19 \\
\hline Estonia & 23 & 64 & 53 & 25 & 45 & 53 & 17 & 25 \\
\hline Ireland & 36 & 70 & 75 & 46 & 48 & 35 & 30 & 21 \\
\hline Greece & 9 & 68 & 58 & 45 & 50 & 18 & 23 & 27 \\
\hline Spain & 18 & 69 & 69 & 59 & 39 & 27 & 29 & 29 \\
\hline France & 17 & 61 & 69 & 55 & 36 & 28 & 29 & 18 \\
\hline
\end{tabular}


International Journal of Computer Science, Engineering and Applications (IJCSEA) Vol. 7, No. 5, October 2017

Table 2: Usage survey of cloud (2012) in different sectors of the USA

\begin{tabular}{|l|l|l|l|l|l|l|l|l|}
\hline & $\begin{array}{l}\text { Small } \\
\text { Business }\end{array}$ & $\begin{array}{l}\text { Medium } \\
\text { Business }\end{array}$ & $\begin{array}{l}\text { Large } \\
\text { Business }\end{array}$ & $\begin{array}{l}\text { Federal } \\
\text { Govemment }\end{array}$ & $\begin{array}{l}\text { State and } \\
\text { Local } \\
\text { Govemment }\end{array}$ & Healthcare & $\begin{array}{l}\text { Higher } \\
\text { Education }\end{array}$ & $\begin{array}{l}\text { K- } \\
12\end{array}$ \\
\hline $\begin{array}{l}\text { Percentage of } \\
\text { organizations } \\
\text { implementing } \\
\text { or } \\
\text { maintaining } \\
\text { cloud } \\
\text { computing }\end{array}$ & $42 \%$ & $40 \%$ & $44 \%$ & $42 \%$ & $27 \%$ & $35 \%$ & $43 \%$ & $42 \%$ \\
\hline
\end{tabular}

Future success of a country relies on the education given to the students of that country. There is a large scope in Bangladesh to apply the cloud in education sector. 131.956 million[21] Bangladeshi people use mobile phones. Needless to say that a significant percent of students also have mobile phones by which they can access cloud services.

Cloud computing provide solutions for the above mentioned problems in education system. It enables users to control and access data via the Internet. The users of an education cloud system include students, Faculty, administrative staff, Examination Branch and Admission Branch as shown in Figure 7. All the main users of the institution are connected to the cloud. Separate login is provided for all the users for their respective work. Teachers can upload their class materials and assignments on the cloud server which students will be able to access. The education system will make it possible for teachers to identify problem areas in which students do make mistakes by analyzing students' submitted copy. It will also allow teachers to improve teaching materials and methods [22].

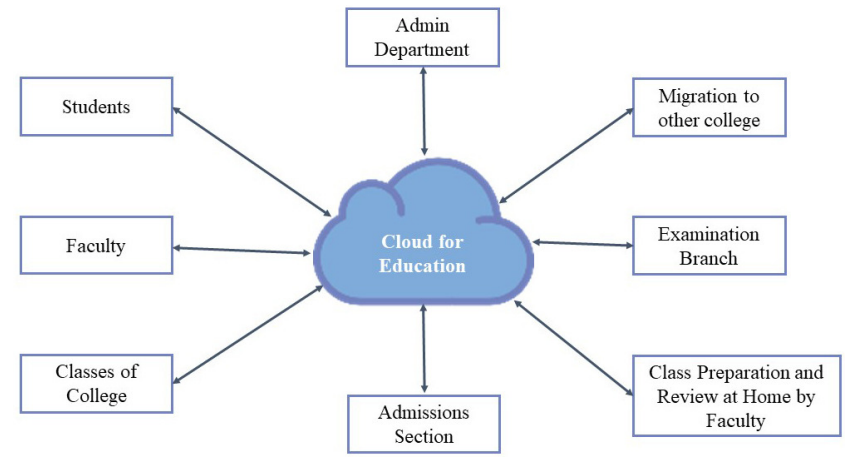

Figure 7: Education system cloud

Cloud in education has many advantages. Most educational institutes are not financially strong. Cloud is a helpful choice for them for reducing IT infrastructure cost. A great advantage of cloud is that the end user doesn't need any specific knowledge about app installation in the cloud or the hardware. All these things are maintained by the service provider so the institute doesn't need any IT person to teach the stuffs about using apps. The future world will be a technology based world so applying the technology in the learning session will help a student to be fully ready for the future world. Thomas J. Bittman of Gartner Research pointed out three advantages of cloud [23].

a) Inexpensive and Free Technology: There has been a enormous growth in inexpensive and free technology for social interaction, publishing, collaborating, editing, content creation, computing, etc.

b) Content Growth: The amount of content is growing at an exponential rate, available to a broad audience, and anyone can contribute. 
International Journal of Computer Science, Engineering and Applications (IJCSEA) Vol. 7, No. 5, October 2017

c) Collaboration: Technology is fast improving the ability to communicate and collaborate with others.

d)

Diane Weaver mentions six advantages of cloud in education in pearsonschoolsystems.com (used here with few alterations) [24].

a) Back Up: An essential function of the Cloud is that it automatically stores content, making it impossible to vanquish or drop any valuable material. This means that even if a user's computer crashes, all content and documents will remain saved, safe and accessible in the cloud.

b) Storage: The Cloud system grants its users to save any kind of content and data including applications, music, eBooks, documents, photos, and much more.

c) Accessibility: Any data can be accessed easily from any device such as mobile, smartphone, computer that is stored in the Cloud.

d) Collaboration: At the same time the Cloud permits multiple users to edit and work on a document, it enables easy sharing and transmission of ideas. With this feature, group projects and or collaborative lesson schemes can be optimized for both students and teachers.

e) Resource and Time Conscious: It is no longer essential for teachers to spend time for resource copying or printing lengthy documents or lesson schemes, with the availability of content online. Now, students are also capable to access assignments, homework, notes, and other components online.

f) Assignments: I love that the Cloud allows teachers to post assignments online. Students are able to access these assignments, complete them, and save them in a folder to be reviewed later. This means no wasting time turning in papers at the beginning of class.

Sameer Bhatia pointed out five advantages of cloud in education in cloudtweaks.com [25].

a) No more expensive textbooks: Everyone know that the university level textbooks are costly. Including university tuition fees, the price of books has exceeded the price of virtually all else in education. As a result, a large number of students are simply unwilling to buy textbook. This problem can be solved by cloud based book and it is also cheaper than printed book.

b) No more outdated learning materials: The materials of textbooks are outdated that is the main problem for students. On the other hand, cloud based materials are up-to-date and also easy to upgrade so that students always have access updated learning materials.

c) No expensive hardware required: Cloud based softwares can be run easily on Internet browsers and most of them are compatible with tablet or mobile devices as well. This means that students and schools are able to use cloud based facilities by using mobile device so that no need to buy expensive laptop.

d) No expensive software required: Cloud based computing has the software as a service model that is the biggest advantage. Most of the softwares are now available free or on a low cost subscription base, so that students can easily use that applications at low cost.

e) Reaching more, and more diverse students: A world of modern probabilities are uncovering by cloud computing for students, particularly those who are not served well by traditional education methods.

These advantages also apply in Bangladesh perspective.

Education rate in Bangladesh is increasing rapidly. Classrooms are being crowded day by day. Teachers cannot take care of the students individually. If cloud system is used in Universities and Schools then students can be benefited a lot and the teachers can give attention to the content quality they are uploading to cloud. The quality contents will help students to learn. 
Consider another scenario, most of the higher education students are financially weak. If an Engineering student or a chemistry student wants to do computing works related to his subject he will need a computer capable of large scale computing which is very costly. But if there is a cloud server which facilitates engineering apps or chemistry apps then the student can do his work with his cheap computer because the computation is done on the cloud server not on his computer. A good example is wolframalpha.com. It's a large computational engine. Building a computational engine like that is not possible for a student but only a normal computer with internet connection is helpful for him to solve his problems using wolfram. This is a huge convenience of cloud computing. Now a days higher educational institutes need to handle a big amount of data, give service to various kinds of devices like tablets-laptops and desktops, deal with scientific data and research. All of these can be easily managed with lower cost using cloud.

\section{OPPORTUNITIES IN BANGLADESH}

Cloud computing has many opportunities for Bangladeshi organizations and industries. Some of them are:

E-learning and e-education is developing by Cloud service: By using cloud computing technology, Bangladeshi organizations and industries can access the educational services participially and beyond the geographic boundaries. This type of access enhance staffs' educational quality.

Recognize e-government and e-voting by using cloud computing service: Cloud computing roles in provision of this type of services is highlighted every day. Bangladeshi government can use these opportunity to enhance its e-government and e-voting.

Service scalability: Aligned with unexpected service demands, cloud computing represents its superior functionality. Cloud computing can answer best to demand changes. In Bangladesh, scalability acts as very influential fact against IT demand changes. This requirements leads to improve IT service provision. In some applications in which this unexpected demand is associated with a period of time, this specification shows most of its functionalities.

Financial efficiency: In Cloud computing structure, customers will pay depending on their service usage. According to cloud service scalability, by using cloud computing, IT infrastructure needs to respond to unpredicted demand will be decreased. In addition, a dramatic decrease in IT costs will occur due to service transition to cloud computing. IT costs such as maintenance, infrastructure and operational costs will be decreased by using cloud computing.

Efficiency in the use of IT: Bangladeshi organizations and IT industries can be more powerful with some features such as the enhancement of IT infrastructure usage, the formation of new economic and technical solution which is impossible without cloud computing, prototyping and acceptance investigate for new paths. In addition, IT services will be more resistant against implantation impendence.

Availability: Cloud computing services are designed to be compatible with network needs. In addition, service availability from anywhere and at any time can increase availability level of Bangladeshi organizations and industries [26].

\section{Case Study And Success Story}

Some case studies are shown below where the cloud system can be used.

Case study: Result day reduce server overload 
Every year when JSC, SSC, HSC or equivalent result is published in Bangladesh, education board server is overloaded with hundreds of thousand requests from all over the country. Every student and their parents have to suffer for this server problem. Thus many students get their results late. If the traditional server which is using for result publication can be updated with cloud server then there will be no delay in result publication as the cloud servers are capable of smart load balancing. Mr. Tamim Shahriar Subeen and Md. Ruhul Amin (Shajib) and their team showed in 2011 that cloud technology is applicable in result publication. They successfully applied the cloud infrastructure to host National University Bangladesh admission test result (2011-12) for more than 400,000 students [27].

Case study: Computers for every school

Recently Bangladesh government has taken initiative plan for distributing computers to schools. Recently computer education is made compulsory for every students. If the primary schools are counted then there are 104017 Primary schools according to 2012 survey of BANBIES and a total student of 19003210[26]. Distributing high power computers to all these schools is a long term process and also expensive but if there is a cloud based system then a \$100 laptop and internet is sufficient for the students. They can learn and do a lot of things using that laptop because all the computing and data storage are done in the cloud server [28].

Case study: Schools for hill-district

Students of Bandarban, Khagrachari and Rangamati are mostly underprivileged in education sector. They don't have good schools, good teachers or good technology. Teachers from town areas are not acquainted with hill district areas like this so they don't want to go there. If a cloud based education system is made for the students of those areas then they will be advanced more in education, modern technology and obviously Bangladesh will be benefited. Grameenphone and Jaago foundation jointly established an online school in Bandarban on March, 2014 [29].

Case study: Google service for education

Google have various cloud apps such as Google drive, slides, docs, sheets etc. On Google drive user can easily store any kind of important data. Google Documents is an online collaborative tools and Google docs is very helpful for students. Google slide is very important for digital classroom. By using Google slides teachers can run presentation file for giving lecture.

Case study: Microsoft Office for education

Microsoft also provide all of their MS Office service on cloud. So students can easily use Microsoft Word, Excel and PowerPoint without install.

Success story: Google classroom and DIU

Google introduced various cloud apps for institutions. Daffodil International University (DIU), Dhaka uses different Google apps for education purpose. One of the apps is Google Classroom. It is very beneficial for students. Recently DIU introduced Google classroom to its students. A survey has been done by the authors of this paper among the teachers and students of DIU and it indicates that all of them are happy with Google Classroom. Teacher and student can have live interactions, assignment submission is easier than ever before. Also teachers are capable to conduct online classes using Google classroom and Google hangout. Learning continues after the class also. Students collaborate with each other, share their knowledge in Google classroom environment. It has also reduced the licensing cost of DIU. The university used another licensed web app for students before using Google classroom.

In Bangladesh there are more than 35 public and 92 private universities which facilitate thousands of students. A big number of these students have internet connection and modern devices and 
with the help of these they can access to Massive Open Online Courses (MOOP) conducted by Yale, MIT, Harvard and other prestigious institutions.

\section{Risks AND ChallengeS}

Increased security vulnerabilities: The transmitting of business data to the cloud means that the responsibility over data security becomes shared with the cloud provider. The remote usage of Information Technology resources needs an expansion of trust boundaries by the cloud consumer to include the external cloud. It can be very hard to set up a security architecture that measure such a trust boundary without introducing vulnerabilities [30].

Reduced operational governance control: Cloud customers are usually allotted a level of governance control that is lower than that over on-premise Information Technology resources. This can introduce risks associated with how the cloud provider manages its cloud, as well as the external connections that are required for communication between the cloud customer and the cloud [31].

Limited portability between cloud providers: Due to a deficiency of established industry standards within the cloud computing industry, public clouds are commonly ownership to various extents. For cloud customers that have custom-built solutions with dependencies on these ownership environments, it can be challenging to move from one cloud provider to another [32].

"Barriers to Adoption" for cloud pointed out by Software Engineering Institute of Carnegie Mellon University. If these challenges can be resolved with the service provider then using the cloud service will be helpful and beneficial [33].

Table 3: Challenges of Cloud Computing

\begin{tabular}{|l|l|}
\hline Security & $\begin{array}{l}\text { The key concem is data privacy: Users do not know where their data is being } \\
\text { stored and they have no control of it. }\end{array}$ \\
\hline Interoperability & $\begin{array}{l}\text { A universal standards about cloud have not yet been defined, resulting in a } \\
\text { significant nisk of vendor lock-in. }\end{array}$ \\
\hline Control & $\begin{array}{l}\text { The quantity of control that the cloud user has over the cloud environment } \\
\text { vanes greatly. }\end{array}$ \\
\hline Performance & $\begin{array}{l}\text { All access to the cloud is done via the intemet, introducing latency into each } \\
\text { communication between the environment and the user. }\end{array}$ \\
\hline Reliability & $\begin{array}{l}\text { Many existing cloud infrastructures leverage commodity hardware that is } \\
\text { known to fail unexpectedly. }\end{array}$ \\
\hline $\begin{array}{l}\text { Platform or Language } \\
\text { Specificity }\end{array}$ & $\begin{array}{l}\text { Some cloud environments provide support for specific platforms and } \\
\text { languages only. }\end{array}$ \\
\hline
\end{tabular}

\section{CONCLuSion}

Cloud computing is a revolutionary technology in modern era. Currently it is an emerging discipline that helps the IT industries to get efficient use of their Hardware and Software resources and enabling service-oriented, on-demand network access to rapidly scalable resources with promises to cut operational and capital cost. It has opened a wider aspect of computing application and provides a global platform for people. It is helpful for every sector from enterprise usage to educational purpose. Traditional classroom (Four walled) seems to be less used in the future. Students will be much benefited. Institutes of weak financial state can have high computing facilities within low cost. After above mentioned discussion, it is clear that Bangladeshi education sector will bloom if the cloud is applied successfully. 
International Journal of Computer Science, Engineering and Applications (IJCSEA) Vol. 7, No. 5, October 2017

\section{REFERENCES}

[1] Thomas Erl with Zaigham Mahmood and Ricardo Puttini, "Cloud Computing Concepts Technology \& Architecture - The Prentice Hall Service Technology Series”, pp. 26.

[2] Wikipedia, "Cloud Computing", Available online: http://en.wikipedia.org/wiki/Cloud_computing, Last Access: 4th August, 2017, 2:56 p.m.

[3] "Cloud Compuitng Gudelines", Available online: https://solutionsreview.com/cloud-platforms/freecloud-computing ebooks, Last Access: 16th May, 2017, 02:04 p.m.

[4] Wikipedia, "Cloud Computing”, Available online: http://en.wikipedia.org/wiki/Cloud_computing, Last Access: 4th May, 2017, 2:56 p.m.

[5] “NIST Cloud Computing Standards Roadmap", Available online: https://www.nist.gov/document4641, Last Access: 16th May, 2017, 10:10 p.m.

[6] "The NIST Definition of Cloud Computing”, Available online: http://csrc.nist.gov/publications/nistpubs/800-145/SP800-145.pdf, Last Access: 4th August, 2017, 3:30 p.m.

[7] Tuncay Ercan, "Effective use of cloud computing in educational institutions", Available online: http://www.sciencedirect.com/science/article/pii/S1877042810001709,Last Access: 5th June, 2017, 10:00 p.m.

[8] Delic, K. A., \& Riley, J. A., "Enterprise Knowledge Clouds: Next Generation KM Systems?", International Conference on Information, Process and Knowledge Management, Mexico, 1-7 February 2009, pp. 49-53.

[9] Rajeev Piyare and Seong Ro Lee, "Towards Internet of Things (Iots): Integration of Wireless Sensor Network to Cloud Services For Data Collection and Sharing”, International Journal of Computer Networks \& Communications (IJCNC) Vol.5, No.5, September 2013, pp. 59-72.

[10] Shin-ichi Kuribayashi, "Reducing Total Power Consumption Method in Cloud Computing Environments", International Journal of Computer Networks \& Communications (IJCNC) Vol.4, No.2, March 2012, pp. 69-84.

[11] "CAREER: Secure and Trustworthy Provenance for Accountable Clouds", Available online: http://www.nsf.gov/awardsearch/showAward?AWD_ID=1351038,Last Access: 28th July, 2017, 6:30 p.m.

[12] Nidal Hassan Hussein and Ahmed Khalid, "A survey of Cloud Computing Security challenges and solutions", International Journal of Computer Science and Information Security (IJCSIS), Vol. 14, No. 1, January 2016, pp. 52-56.

[13] Tuncay Ercan, "Effective use of cloud computing in educational institutions", Available online: http://www.sciencedirect.com/science/article/pii/S1877042810001709 ,Last Access: 5th August, 2017, 10:00 p.m.

[14] Anjali Jain \& U.S Pandey, "Role of ClouD Computing in Higher Education", Available online: http://www.ijarcsse.com/docs/papers/Volume_3/7_July2013/V3I6-0242.pdf,LastＡccess: 5th September, 2017, 10:15 p.m.

[15] "Cloud Computing in Education, a Microsoft U.S. education whitepaper",Available online: http://www.aicte-india.org/downloads/CloudComputinginEducation.pdf,Last Access: 10th June, 2017, 8:00 a.m.

[16] "Cloud Computing in Education, policy brief 2010", Available online: http://iite.unesco.org/pics/publications/en/files/3214674.pdf, Last Access: 7th June, 2017, 8:55 a.m.

[17] Google, “About Us”, Available online: http://www.google.com/about/company/history/, Last Access: 28th May, 2017, 10:00 p.m. 
International Journal of Computer Science, Engineering and Applications (IJCSEA) Vol. 7, No. 5, October 2017

[18] "Roundup of Cloud Computing Forecasts and Market Estimates, 2016",

Available online: https://www.forbes.com/sites/louiscolumbus/2016/03/13/roundup-of-cloudcomputing-forecasts-and-market-estimates-2016/\#513d2e4f2187,Last Access: 17th May, 2017, 10:00 a.m.

[19] "Cloud computing services", Available online: http://appsso.eurostat.ec.europa.eu/nui/show.do?dataset=isoc_cicce_use\&lang=en, Last Access: 17th May, 2017, 10:30 a.m.

[20] "Cloud Computing as an Emereged Technology", Available online: https://josephvermeille.wordpress.com/tag/statistics-on-the-rate-of-adoption-of-cloud-computing/, Last Access: 17th May, 2017, 09:10 p.m.

[21] Mobile Phone Subscriber Statistics, Available online: http://www.btrc.gov.bd/content/mobile-phonesubscribers-bangladesh-january-2016, Last Access: 18th May, 2017, 09:10 a.m.

[22] "Role of Cloud Computing in Education", Available online: https://www.ijircce.com/upload/2014/february/21_Role.pdf, Last Access: 18th May, 2017, 11:00 a.m.

[23] "Cloud Computing and K-12 Education",

Available online: http://blogs.gartner.com/thomas_bittman/2008/11/26/cloud-computing-and-k-12education/, Last Access: 15th June, 2017, 11:28 a.m.

[24] "The Roadmap to Successful Formative Assessment Implementation", Available online: http://www.pearsonschoolsystems.com/blog/?p=1507\#sthash.7ckm5nIN.dpbs, Last Access: 17th June, 2017, 11:50 p.m.

[25] "5 surprising ways cloud computing is changing education", Available online: https://cloudtweaks.com/2014/12/cloud-computing-education-growth/, Last Access: 18th May, 2017, 10:15 p.m.

[26] "Cloud Computing Technology in Iran: Opportunities, Threats", Available online: http://wp.kntu.ac.ir/mohammadi/4.pdf, Last Access: 31th May, 2017, 12:14 p.m.

[27] "Website Calamity and Solution", Available online: http://subeen.com/ওয়েবসাইট-বিপর্যয়-ও-মুক্ত-2/ (https://goo.gl/18ZQsf), Last Access: 20th June, 2017, 4:00 p.m.

[28] "Computer Distribution Gallery", Availableonline:http://www.moedu.gov.bd/index.php?option=com_content\&task=view\&id=300\&Ite mid=301, Last Access: 28th June, 2017, 10:30 p.m.

[29] "Bandarban children see a ray of light", Available online: http://www.thedailystar.net/bandarban-children-see-a-ray-of-light-16369, Last Access: 3rd November, 2014, 6:25 p.m.

[30] Thomas Erl with Zaigham Mahmood and Ricardo Puttini, "Cloud Computing Concepts Technology \& Architecture - The Prentice Hall Service Technology Series”, pp. 45.

[31] Thomas Erl with Zaigham Mahmood and Ricardo Puttini, "Cloud Computing Concepts Technology \& Architecture - The Prentice Hall Service Technology Series”, pp. 45.

[32] Thomas Erl with Zaigham Mahmood and Ricardo Puttini, "Cloud Computing Concepts Technology \& Architecture - The Prentice Hall Service Technology Series”, pp. 47.

[33] "Cloud Computing: Barriers to Adoption", Available online: https://www.sei.cmu.edu/sos/research/cloudcomputing/cloudbarriers.cfm. Last Access: 5th July, 2017, 1:00 a.m. 